This item was submitted to Loughborough's Research Repository by the author.

Items in Figshare are protected by copyright, with all rights reserved, unless otherwise indicated.

\title{
The impact of contingency factors on validation of problem structuring methods
}

PLEASE CITE THE PUBLISHED VERSION

http://dx.doi.org/10.1057/jors.2009.94

\section{PUBLISHER}

Palgrave Macmillan / @ Operational Research Society Ltd

\section{VERSION}

AM (Accepted Manuscript)

\section{PUBLISHER STATEMENT}

This work is made available according to the conditions of the Creative Commons Attribution-NonCommercialNoDerivatives 4.0 International (CC BY-NC-ND 4.0) licence. Full details of this licence are available at: https://creativecommons.org/licenses/by-nc-nd/4.0/

\section{LICENCE}

CC BY-NC-ND 4.0

\section{REPOSITORY RECORD}

Champion, Donna, and John M. Wilson. 2019. "The Impact of Contingency Factors on Validation of Problem Structuring Methods”. figshare. https://hdl.handle.net/2134/18611. 
The impact of contingency factors on validation of problem structuring methods

D Champion and J M Wilson

Business School

Loughborough University

LE113TU

April, 2009

d.champion@lboro.ac.uk j.m.wilson@lboro.ac.uk

\begin{abstract}
Although much has been written about validating DSS and other 'hard' OR models, less has been written about validating 'soft' OR models. This paper seeks to determine which contingency factors known to influence DSS validation are also important factors influencing PSM (problem structuring methods) validation. In addition, after consultation with PSM experts other contingency factors influencing PSM validation are proposed. Evidence from these PSM experts concerning the levels of influence of these factors is used to support proposals for a contingency approach to PSM validation.
\end{abstract}

Keywords: Problem structuring methods, validation 


\section{Introduction}

Over the last two decades there has been interest in the validation of models in OR. Several validation frameworks have been developed including those by Landry et al (1983), on which associated developments appear in Dery et al (1993), Miser (1993) and Oral and Kettani (1993), Finlay and Wilson (1997) and Olphert and Wilson (2004). The latter authors and their co-authors have made various contributions to the literature on model validation in the papers Finlay and Wilson (1987), Finlay and Wilson (2000) and Anastasakis et al (2008). For the purposes of Finlay and Wilson (1987) and the later papers by these authors, the definition of validation was that taken from Fishman and Kiviat (1968) that “model validation tests the agreement between behaviour of the model and the real world system being modelled”. For verification of computer-based models the definition of Gass (1983) was used: "the process of demonstrating that the computer program 'runs as intended"' and for the purposes of discussion it was assumed that verification would be taken to be a subsidiary task in the process of validation. One point of departure of Finlay and Wilson (1987) was that, although the formative model building experiences of one of the authors had been in building large simulation models in the defence industry, the validation procedures developed and used for such models did not transfer naturally to other situations where models were smaller, less structured, less quantitative, and involved different modelling techniques than simulation. Some OR validation procedures grew up based on US government policy modelling, and while of some relevance for simulation modelling are not transferable generally (USGAO, 1979). Simulation models can be carefully validated in a structured way heavily grounded in statistical techniques, but such approaches were inappropriate for many other types of models. For details of current thinking on simulation models, including their validation, see Robinson (2008).

In the papers Finlay and Wilson (2000) and Anastasakis et al (2008) much of the concentration has been on validating decision support systems (DSS) embedded in spreadsheets. However, although the validity of the methodology was only claimed for spreadsheet DSS, it was suggested in Anastasakis et al (2008) that most elements of the methodology were likely to be relevant for many more forms of DSS. In the 
above mentioned validation frameworks, the focus is appropriately on what has traditionally been thought of as 'hard OR'(which is perhaps better described as 'problem solving' OR) but clearly validation will be important in problem structuring activities (or those approaches traditionally described as 'soft OR') and arguably it is a much more dominant phase in a soft systems approach than in problem solving OR. In particular, an important role for the participants in problem structuring methodologies (PSM) such as soft systems methodology (SSM) (Checkland, 1999), is one of conducting or encouraging validation during an inquiry process, though others (see for example, Pala et al, 2003) have argued that 'validity seems to play a minor role' in such approaches; so one of the aims of this paper will be to determine whether validation is neglected in problem structuring methodologies (PSM).

Traditional approaches to evaluation in OR can ignore the unique strengths and weaknesses of PSM. Rosenhead (2006) has suggested that a wider acceptance and exploitation of PSM is important if the potential of soft OR is to be realised in practice. Applying some of the lessons learnt from applying PSM would suggest that the unique characteristics of problem structuring in complex organizational settings requires a holistic approach to validation that is rigorously based on theory, but that is also practical and easy to use for practitioners in the field (Champion, 2007; Champion et al, 2005). Validation approaches for PSM also need to offer some means of establishing the legitimacy of the process of inquiry, as many of the outcomes of such inquiry are subjective in nature and not amenable to quantitative analysis or measurement (Champion and Stowell, 2003; Midgley, 2000). As will be discussed in more detail in Section 3, for the purposes of this paper a PSM will be taken to be valid if the way in which the inquiry process was undertaken has been validated and any tangible outcomes have also been validated. For such outcomes the validation process will follow traditional approaches developed for DSS validation.

In this paper we will consider approaches to the validation of PSM that have been applied, focusing on the approaches to validation suggested in two special editions on PSM published in the Journal of the Operational Research Society (57:7 July 2006 and 58:5 May 2007). We investigate what parts of DSS validation methodology are transferable to the soft aspects of PSM in particular and consider what additional approaches might be required for the development of PSM validation frameworks. 
This paper is also the result of a dialogue concerning validation between two authors who have each adopted very different approaches to validation in their own work. One of us has investigated validation models in OR, primarily focusing on the validation of decision support systems and the other author has investigated validation approaches to PSM primarily in the context of action research projects. This dialogue has been enhanced by additional evidence from PSM experts in support of factors that influence PSM validation. Based on this evidence, we then make some suggestions for what aspects of a contingency approach are applicable to the validation of a PSM guided inquiry. We also suggest that creating a framework for PSM validation that incorporates elements from a contingency approach as part of the validation process would facilitate the work of multi-disciplinary groups, as it would offer an approach to validation that addressed the concerns of practitioners from a wide range of backgrounds and disciplines. First, we consider the elements necessary for a validation methodology.

\title{
2. The elements of a validation methodology
}

In Finlay and Wilson (2000) the elements of end-user DSS validation were identified as

\author{
Validation of the logic model \\ Validation of the data model \\ Validation of the system builder \\ Validation of the interface \\ General (holistic) validation.
}

Finlay and Wilson (2000) also postulated that these elements will need to be validated at a level of intensity determined by contingency factors. For example, an OR project to develop a long-term plan should lead to different amounts of and types of validation from a project to make a short-term decision. The elements of validation set out above will be examined and their role in PSM will be considered. Table 1 illustrates where the emphasis for validation is likely to fall for Soft Systems Methodology (SSM), as the most widely known and used PSM when compared with DSS. 
Table 1: Requirements for validation in DSS and PSM

\begin{tabular}{|c|c|c|c|c|}
\hline Validation type & \multicolumn{2}{|c|}{ DSS model } & \multicolumn{2}{c|}{$\begin{array}{c}\text { PSM 'model' } \\
\text { (SSM guided Inquiry) }\end{array}$} \\
\hline Logic model & $\mathrm{Y}$ & $\geq$ & $\mathrm{Y}$ & \\
\hline Data model & $\mathrm{Y}$ & & $\mathrm{A}$ & \\
\hline Interface & $\mathrm{Y}$ & & $\mathrm{N}$ & \\
\hline System Builder & $\mathrm{Y}$ & & $\mathrm{Y}$ & $\geq$ \\
\hline General (holistic) & $\mathrm{Y}$ & $\geq$ & $\mathrm{Y}$ & \\
\hline
\end{tabular}

$\mathrm{Y}=$ present, $\mathrm{N}=$ absent $\mathrm{A}=$ Sometimes applicable (See Table 2).

$\geq$ = probably more important in the column in which it appears (when both), and certainly no less important.

Here we have compared a traditional OR approach to developing a DSS with SSM, and focused on 'model-building' validation, as it is in the process of model building that the two approaches have a subtle difference in approach. Checkland (1995) argues that the models created during an SSM guided inquiry are intended only to be relevant to debate and should not be regarded as representing or mapping any part of the real world. This approach to model building is different to that used in the development of DSS where there is a focus on creating representations of current or proposed processes in order to build a new system. One would then anticipate there to be significant differences between the approaches used for model validation between DSS and PSM. The expected differences in the type of validation between DSS and PSM approaches are illustrated in Table 2.

Table 2: Differences in conduct of validation in DSS and PSM

\begin{tabular}{|c|c|c|}
\hline Validation type & DSS model & 'SSM (PSM) model' \\
\hline Logic model & $\begin{array}{l}\text { The Logic Model acts as a } \\
\text { representation or 'map' of } \\
\text { the logic of the new system } \\
\text { verified through } \\
\text { simulations and formal } \\
\text { checks. }\end{array}$ & $\begin{array}{l}\text { Models are created as devices that } \\
\text { illustrate problem issues sufficiently } \\
\text { to encourage and support debate } \\
\text { amongst participants. The models } \\
\text { are validated through reaching an } \\
\text { appreciation of the problem and } \\
\text { ideas for potential ways forward } \\
\text { amongst the group. }\end{array}$ \\
\hline Data model & $\begin{array}{l}\text { Representation or 'map' of } \\
\text { the data required for the } \\
\text { new system verified } \\
\text { through simulations and } \\
\text { formal checks. }\end{array}$ & $\begin{array}{l}\text { A data model can sometimes be } \\
\text { created e .g. if stakeholder analysis } \\
\text { is applied. In Client Led } \\
\text { Information System Creation } \\
\text { (CLIC, Champion et al, 2005) an } \\
\text { SSM guided approach to IS }\end{array}$ \\
\hline
\end{tabular}




\begin{tabular}{|c|c|c|}
\hline & & $\begin{array}{l}\text { development, a type of conversation } \\
\text { modelling is used to create a data } \\
\text { model during the design phase. }\end{array}$ \\
\hline Interface & $\begin{array}{c}\text { End-user will act as guinea } \\
\text { pig }\end{array}$ & $\mathrm{n} / \mathrm{a}$ \\
\hline System Builder & $\begin{array}{l}\text { Meetings periodically with } \\
\text { end-user }\end{array}$ & Works alongside end-user \\
\hline General (holistic) & $\begin{array}{l}\text { The models are developed } \\
\text { mainly by expert } \\
\text { practitioners and validated } \\
\text { through formal procedures } \\
\text { that require user input }\end{array}$ & $\begin{array}{l}\text { The models are developed and } \\
\text { agreed through collaborative } \\
\text { inquiry; the models can also be used } \\
\text { to recover (Checkland and Holwell, } \\
\text { 1998) the PSM process for } \\
\text { validation purposes. }\end{array}$ \\
\hline
\end{tabular}

PSM are most often applied in problem situations which are, at least at the start of an inquiry process, unstructured and complex with a considerable degree of subjectivity and where participants in the inquiry process hold a range of diverse opinions and viewpoints. The validation process in PSM guided inquiry is then a much more complex process and this is discussed below.

\section{The validation process in PSM}

PSM are most often applied in situations where there is a significant degree of uncertainty about what particular issues are creating difficulties for those involved, and/or about what possible ways there might be to bring improvement to a difficult situation. Champion (2007) also points out that action taken as a result of PSM guided inquiry often impacts upon those in the wider environment and so when working within a PSM framework it is also important to establish the legitimacy and authenticity of the inquiry process itself and not just focus on any tangible outcomes (Champion and Stowell, 2001; Champion, 2008). The concept of legitimacy refers to the need in PSM to establish that the way an inquiry process was undertaken can be justified. Champion and Stowell (2003) refer also to a concept of authenticity where they suggest inquiry must be undertaken by participants who take on full responsibility for their actions and reflect on the reasons and motivations for choices and decisions. Undertaking problem structuring activity then is very different to traditional approaches to constructing a technology-based system for decision support, 
where participants might be asked questions about objectives, constraints, data values reliability of forecasts, and so on. For example, in SSM, Checkland (1999) argues that it is important to work within an action research (AR) framework whilst undertaking problem structuring, in order to ensure the sense making experience will be meaningful for participants, and to offer research outcomes that can be seen to have been gleaned directly from the practical work undertaken in the field. As might be expected Checkland has written about the validation issue.

Checkland (1985, p. 758) has offered the FMA model through which to organize AR (and so also SSM), in order to facilitate scrutiny by interested others, where a set of “...linked ideas in a framework $\mathrm{F}$ can be applied by using a methodology $\mathrm{M}$ to explore an area of concern A". For the learning outcomes of inquiry within complex and fluid social situations to be accepted as useful lessons, Checkland (1985) argues that the elements of the FMA model must all be declared in advance of any intervention in the field. Checkland and Holwell (1998) also suggest that a notion of recoverability is essential to establishing the validity of a PSM intervention and they suggest that an open declaration of the aims of the inquiry and also of the intended research method, prior to involvement in the situation of interest is necessary so others can 'recover' the route of the inquiry. This approach has been criticised by Dash (1999) who argues that it is still easy to evade the longer term consequences of an intervention. The FMA model has also been criticised by Champion and Stowell (2003) as they argue that this approach does not provide any insight into the manner in which the inquiry is undertaken, such as who participated and why; what methods were used and why; who authorised the inquiry; and crucially which relationships were changed as a result often remains unclear; it is these softer aspects of problem structuring approaches that can make the difference between a perception of quality and validity, or a perception of failure. Romm (1996) also pointed out that the outcomes of PSM need to be checked using criteria from other approaches to prevent the problems of groupthink, or a lack of knowledge on the part of participants. This resonates with the contingency approach for DSS validation that will be discussed later in the way it applies to PSM.

Midgley et al (2007) have also begun the development of a framework in which to evaluate the success of PSM, though their aim is to conduct a comparison across methods and across case studies. They suggest an evaluation framework that focuses 
attention on three elements: the purpose of the intervention (for decision makers and stakeholders), the context and the methods used (including participants' experience of these). Midgley et al (2007) suggest that these three elements are important to developing “....understanding of how a method has operated in a particular case study of practice”. Checkland (1999) has argued that any attempt to generalize between different applications of a methodology is misguided as each particular situation is unique to the participants and facilitators involved. This is an important point, because although PSM involve the stakeholders to a significant degree in the modelling process and stakeholders have the opportunity to verify and validate models during the design process, there may be tension if there is disagreement over the purpose and aim of a problem structuring intervention at the start. Stakeholders may be able to decide 'where things are going' more readily during soft systems approaches, however, they may not know what questions to ask to help validate the PSM process partly because they are so deeply immersed in its process. Indeed (as one of the authors found in an internal facilitated exercise) the process may itself be the outcome, rather than the original aims proposed at the start of an intervention, because the learning that occurs during problem structuring can lead to new aims being designed and unanticipated outcomes being achieved.

In further work by Ormerod (2007), he describes what he calls the transformation competence perspective - the transformation a project aimed to achieve and the competence of the stakeholders and consultants to achieve these aims - and in discussing validation he states that "the validation of the transformation competence perspective thus lies in experience not theory”. This approach then also draws on the concepts of legitimacy and authenticity even though it is not overtly stated.

Our purpose here is to evaluate which elements of DSS validation methodology can be usefully applied when undertaking problem structuring in social settings and to set out what additional approaches to validation are required in order to establish the appropriateness, relevance and quality of the soft aspects of problem structuring in social situations. In particular, we seek to establish which contingency factors need to be included within a framework such as Midgley et al. (2007). First, we examine which aspects of DSS validation approaches are applicable to PSM. 
Applying DSS Validation Methodologies to PSM

The following contingency factors (with key word, or phrase, of short version emboldened) were identified in Olphert and Wilson (2004) for spreadsheet DSS as being principal factors affecting validation:

1. Level of risk/importance of decision;

2. Complexity of system/problem being modelled;

3. Significance of DSS to decision;

4. System builder competence;

5. Contentiousness of decision;

6. Probability of system re-use;

7. Decision deadline;

8. Number of potential users.

Our first concern for the appropriateness of DSS validation methodologies for PSM is to consider whether PSM validation effort should vary in proportion to the above eight factors; in Olphert and Wilson (2004) these eight factors were identified as having decreasing influences on DSS validation in the rank order as presented as 1-8.

1. Level of risk/importance of decision; This factor would seem to be relevant even for PSM and would surely become apparent during any interactive sessions. Validation can be undertaken in varying intensities reflected in the use of, for example, more focus groups; wider consultations; workshop or feedback sessions.

2. Complexity of system/problem being modelled;

This aspect will come across in the complexity of diagrams and other representations used in PSM approaches. Care and attention can be reduced/increased when it becomes clear how complex (or otherwise) things are perceived to be, or how many different perspectives on the issues to be addressed need to be considered. However, modellers must be clear that the complexity of modelling and the complexity of the problem issues are commensurate.

3. Significance of DSS to decision; 
Here there will be a difference. PSM guided inquiry will not necessarily be associated with the development of a DSS. If a DSS is developed as an outcome of the PSM process, this activity is usually undertaken at a later stage of the inquiry process. Thus the effort put into the PSM process will not be connected with the subsequent significance of the DSS (i.e. its use in the decision making may have little connection with the stages of the PSM - this will emerge later). The need for a DSS may be an outcome of PSM and this may then influence the conduct of the PSM process, but not in the way that the building of a mathematical model influences DSS development.

Problem $\rightarrow$ PSM $\rightarrow \quad$ Structured problem $\rightarrow \quad$ Outcome

(which could include a DSS)

\section{System builder competence;}

The role of a PSM facilitator will be significantly different to that of the system builder in DSS development. The competence of the facilitator in PSM can be established in terms of previous experience especially experience of this type of inquiry. The competence of the facilitator will come across much more to the client during the 'modelling' stage because stakeholders will be working alongside the facilitator. How will this influence the need for validation? Experienced modellers will be able to ensure that the necessary aspects of validation are implemented, but this will more be in the hands of the facilitator than the stakeholders, an issue raised in Champion (2007), where she argues for more inclusive evaluation tools to be developed that can be applied by stakeholders themselves.

\section{Contentiousness of decision;}

Contentiousness should be reflected during the stages of the facilitation process and will come across during problem structuring sessions. The proportionality of levels of difficulty of problem to level of validation should be able to be handled in a reasonably straightforward way during the problem structuring process and time spent on validation will be a fair reflection of expectations.

\section{Probability of system re-use;}

Again, this will depend largely upon whether a DSS is an outcome of a PSM guided inquiry and will be difficult to anticipate. 


\section{Decision deadline;}

This will be a difficult factor to handle when tight. When the deadline is tight for a mathematical modelling exercise, there may be the possibility of extra resources being thrown at the problem to speed the work - modellers may have this capacity. With a PSM approach, bringing people together will be part of the process, so flexibility may not exist and it may not be possible to do the work on time. Renegotiation of deadlines may be important. However, experience of using PSM in practice has shown that the difficult and time consuming start up of a project often leads on to a much more efficient, effective and quick implementation (Champion et al, 2005). Using such approaches in practice can seem to take longer at the start, but because of the shared appreciation that grows amongst participants, a synergy develops that can lead to projects being finished ahead of time. There are no set rules when applying PSM, each situation is unique. One role of the facilitator in PSM ought to be managing expectations (Champion, 2007), so that if the time for exploration is cut short due to imposed time constraints, the group accepts that this will increase the risk of the outcome not being as carefully explored and considered.

\section{Number of potential users.}

The number of users as a factor will be reflected in the size, or number, of group discussions and so on, and thereby so will the modelling effort. Having a large number of potential users will mean more people need to get involved (unless users are at quite a low level). This will particularly apply when assessing 'the results of the study' which will be a different process when a PSM is applied to the case where a DSS is an outcome. Again, experience of applying PSM in practice would suggest that during problem structuring it is not only the so called 'users' of a new system that need to be taken into consideration. A number of authors have argued that it is important to take a wide perspective when considering the outcomes of a collaborative learning process (Churchman, 1970; Ulrich, 1993). Champion and Stowell (2003) make the point that non-participants can also often be impacted by, or concerned with, the outcomes, whether they were involved in the learning process, or not, and that it is not always possible to include everyone in the user group; they suggest that sometimes a boundary around participation is needed and that such a boundary will then need to be explained and justified. Connell (2001) tries to resolve 
the issue of lack of clarity about identification of 'users' by constructing a 'participation matrix'.

The eight contingency factors are illustrated schematically in Figure 1 with + or used to indicate that a greater (lesser) level of the factor will lead to a need for more (less) DSS validation. Factors impacting on PSM validation will be considered later.

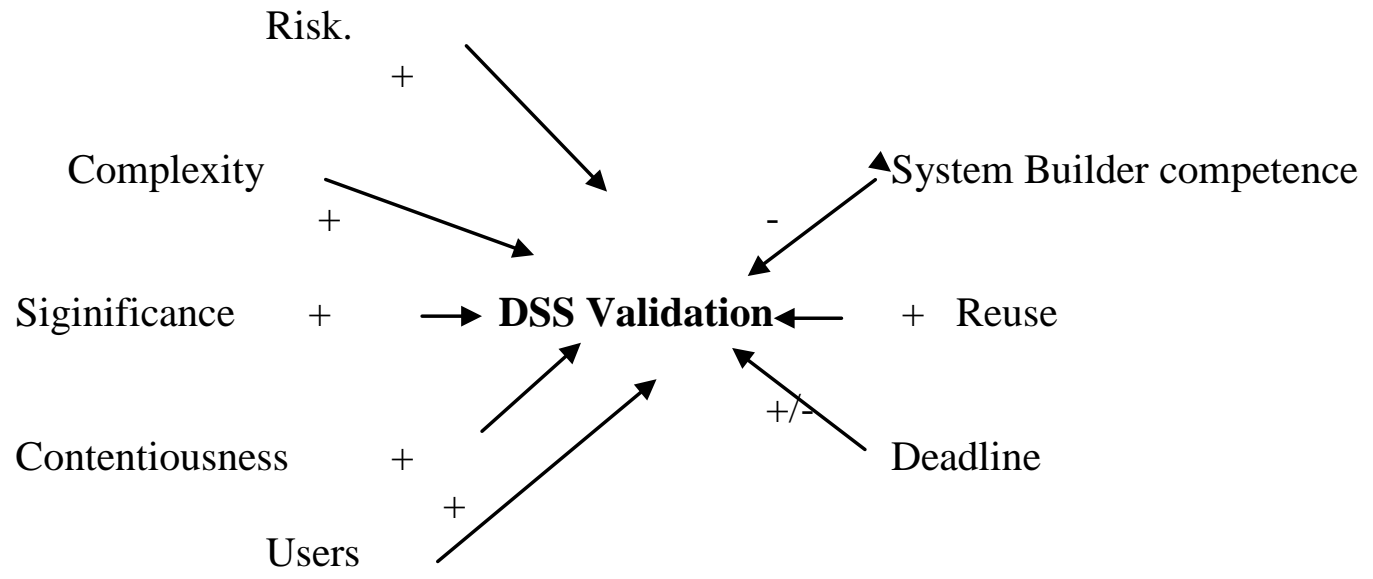

Figure 1

\section{The experience of others}

In this section we will consider the nature and extent of validation as mentioned by a selection of authors in recent papers published in this journal. The two special issues on Problem Structuring Methods (57:7 July 2006 and 58:5 May 2007) collect together a set of valuable papers on PSM offering much advice on the way to use PSM and describing many of its advantages. For the purposes of this paper it is of interest to see where papers in these issues mention validation (perhaps not using the same word, but an equivalent or loose-equivalent). We suggest that the papers in these two issues represent an important step in promoting and explaining PSM and therefore their authors' views on the conduct of PSM are influential.

In two papers in the sets validation is mentioned explicitly. First White (2006), quoting earlier work by Finlay (1998) states that "experimental validity must be sought”. White stresses "a pragmatic theory-based approach to evaluating PSM”. His case is one of community OR, but using ideas from Pawson and Tilley (1997) 
provides a form of validation framework employing the stages Plausibility/Doability/Testability/Meaningfulness. Secondly, den Hengst et al. (2007) mention validation several times, including what they term 'black-box validation'. Their paper suggests the use of a 'hard' technique (simulation) to assist in a 'soft' situation. Validation has long been closely associated as a key element in simulation modelling, so it is not surprising that in this paper it features strongly when the authors consider the interface between group support and discrete event simulation.

In several papers themes are mentioned which might be taken to imply validation by another name. In Montibeller and Belton (2006) 'pros' and 'cons' of approaches to evaluate options in causal map-based interventions are discussed and these imply a search for validity. In Winter (2006) one retail store is used for building a prototype model for project management, thereby contributing implicitly to validity. Franco (2006), in using conversation techniques, discusses "claims of legitimacy or rightness" which seems a partial synonym for validity, while Shaw (2006) discusses generating confirmable findings in journey making workshops. In O’Brien and Meadows (2007) there is mention of the need to "check for internal consistency and plausibility” in a visioning approach, although there is no explicit mention of how to achieve this goal. Finally, in Vo et al. (2007) it is apparent that the consensual approach used in unbounded systems thinking has an element of inbuilt validation.

Thus it is clear that in a number of these PSM papers describing methodology or cases the authors are mindful of the need for validation, even if the term is not explicitly used. In four other papers in the sets there is a sense of a contingency approach to validation coming through. First, in Ritchey (2006) there is mention of a 'quick method' and a 'thorough method' for cross-con, which has resonance with a contingency factor approach to validation. Second, in Keys (2006) the author mentions that the presence of an expert/non-expert modeller will make a difference, an aspect claimed in Section 3 factor 4 of this paper as an influence on DSS validation. Third, Morton et al. (2007) state that they “do not think there is a universally correct level of involvement which a client should have in a PSM process ... depends on the trade-offs ...”. This seems a clear indication of a contingency view to PSM validation. Fourth, Papamichail et al. (2007) in a paper on facilitation are 
conscious of looking for instances where decision workshop sessions can be simplified, implying a contingency view.

Overall, from this doubtless flawed interpretation of other writings, the claim is made that there is a considerable awareness of the need for validation, but not necessarily any advice offered on how to perform it, within PSM either explicitly or implicitly and there seems to be deducible a sense of a contingency view of PSM validation. These distilled views give us confidence to seek expert opinion from PSM developers on what factors will influence validation and this will be explored in the next section.

\section{Differences in PSM validation}

A set of additional contingency factors is now listed which is felt by the authors to be necessary for PSM but was not appropriate for spreadsheet DSS. These factors are ones which receive support in the literature:

1. Experience of stakeholders. PSM are designed to be used in a collaborative manner, bringing together the experience and expertise of a wide range of people who are involved in a particular problem situation. PSM tend to involve non-managerial groups in the inquiry process and this can be a very positive experience for such staff leading to their skill base being extended (Bødker, 1996) and relationships within an organization being strengthened. But Rosenhead (2006) points out that such an approach to problem solving can only work if participants devote significant amounts of time to the process and this can be regarded as a less effective use of resources than the alternative approach which is to use a small team of experts to address a problem.

2. Organisational structure. Rosenhead (2006) suggests that traditional OR works well when the client organization is structured as a tight hierarchy, addressing problems that use reliable data in well-defined processes. PSM though seem to be used in more complex environments where there are "significant intangibles [and] perplexing uncertainties” (Rosenhead, 2006). This adds to the difficulty of finding ways of validating both the PSM process and any outcomes. In large complex environments it also adds to difficulties when deciding who to include in the PSM 
process. Most authors advocate the involvement of the entire relevant group when undertaking a PSM (See Checkland and Holwell, 1998; Taket and White, 2000), but in large groups it becomes necessary to put a limit on numbers and this presents the problem of who to select from various levels of an organization and justifying that selection (Champion and Stowell, 2003), hence the type of organizational structure may well impact on the process of validation.

3. Influence of external environment. Advocates of collaborative modes of inquiry are often driven by the belief that people on the receiving end of problems can simply choose to behave differently (See for example, Märtensson and Lee, 2004). When applying PSM in practice there can be an emphasis on gaining accommodation, or consensus amongst the group on a way forward to hopefully improve a situation. But choosing between alternatives is an option that is not always open to us “...understanding may or may not, be followed by the hope that something can be done to make the situation better or to stop it getting worse” (Vickers, 1983). Indeed difficulties can often be created through social and environmental factors "which have their origin at some considerable distance from those ultimately subjected to them” (Smail, 2001, p.160). Indeed Mingers (1980, 1984) and Jackson (1982) have both emphasized the need to take into account societal constraints when conducting SSM guided inquiry. Rosenhead (2006) though does make a strong case for PSM having an important contribution to play in helping leaders to manage turbulence in the current climate of global economic uncertainty; either way it seems that external factors will impact upon the process of achieving validation of both the PSM process and any outcomes.

4. Type of outcome sought including nature of any deliverables (e.g will a DSS be built? Will a decision be taken?). Often traditional OR is applied in situations where there is a clear deliverable expected, whereas PSM guided inquiry is much more open-ended. From the 1980s onwards a large body of work has been published discussing how SSM could be linked up with more formal methods of software development in order to develop information systems (see Champion, 2001, and Holwell, 1997 for overviews of this literature). The literature on applying SSM to the problem of IS development would suggest that the type of outcome being sought does indeed impact on the approach to validation that should be adopted, participative 
methods alone are not sufficient to validate a technical system (Champion et al, 2005).

5. Politics and personalities of who is involved: Kotiadis and Mingers (2006) suggest that traditional OR methods tend to appeal to an analytical scientist type personality and using PSM type methods might not appeal in a technically-focused environment; they suggest that PSM are preferred by humanist type personalities who value personal involvement and working in teams (see also Gregory and Jackson, 1992a, b). A quick scan through the weekend job pages though confirms that companies today recognise the need for both types of skills and they look for people who can combine technical and soft skills. Rosenhead (2006) also points out that Government has become more reliant on contracting for services to achieve delivery, acting as an incentive for co-operative behaviour (see also Ciborra, 2002).

6. Length of history of the problem; i.e. is it a long term problem or is it evolving? Rosenhead (2006) suggests that longer term problems tend to be organizational, rather than technical, and that traditional approaches to OR offer very little in the way of support to senior management due to the complexity and subjective nature of the more complex problems to be addressed at this level. He suggests that this would imply there is a deficiency in the scope of applicability for traditional OR and that PSM may offer means to "engage with aspects of organizational functioning”. It is widely accepted that PSM are useful in addressing complex messy problems but Dash (1999) has criticised SSM for evading the longer term consequences of any intervention and this criticism can be extended to other PSM frameworks too. Champion (2007) suggests that when validating PSM (which will include establishing the legitimacy of the PSM process), it is important to consider the longer term consequences and for the validation process not to be a single, one-off event, but an ongoing collaborative process involving stakeholders.

7. Factors involved with implementation difficulty. Rosenhead (1996) states that the “non-transferability of the workshop experience can cause implementation problems". Champion (2007) however adopts an interpretivist approach to problem structuring and suggests that as social situations are unique, success cannot be guaranteed no matter what methods or approach are applied (see also Checkland, 1995), and so a 
quest for repeatability, or transferability is mistaken. Champion (2001; 2007; Champion and Stowell, 2003) has developed PEArL, an evaluation framework, that facilitates both stakeholders and crucially, people not involved in the PSM process, but who are interested in the implications or outcomes, in assessing both the inquiry process and any practical outcomes for themselves, which she argues can help to address any problems with implementation as they arise.

8. Type of PSM being used. Some authors suggest that when undertaking PSM it is important to be logically consistent and to remain within one particular approach to inquiry (see Checkland, 1999; Jackson, 2000), but Midgley (1989, 1990, 2000) argues that methods and tools can be mixed and that a pluralist approach is the most versatile tactic to adopt when addressing complex problems (see also the work of Mingers, 2003). It seems that the underlying principles of inquiry applied by the practitioners of PSM will impact on how they undertake validation and which issues they consider to be the most important. The work that Midgley et al (2007) are currently undertaking on developing a framework to compare the success of different PSM across methods and across case studies might hopefully provide some additional insight here in the future.

These eight factors are illustrated in Figure 2 with indications of their type of influence on validation effort.

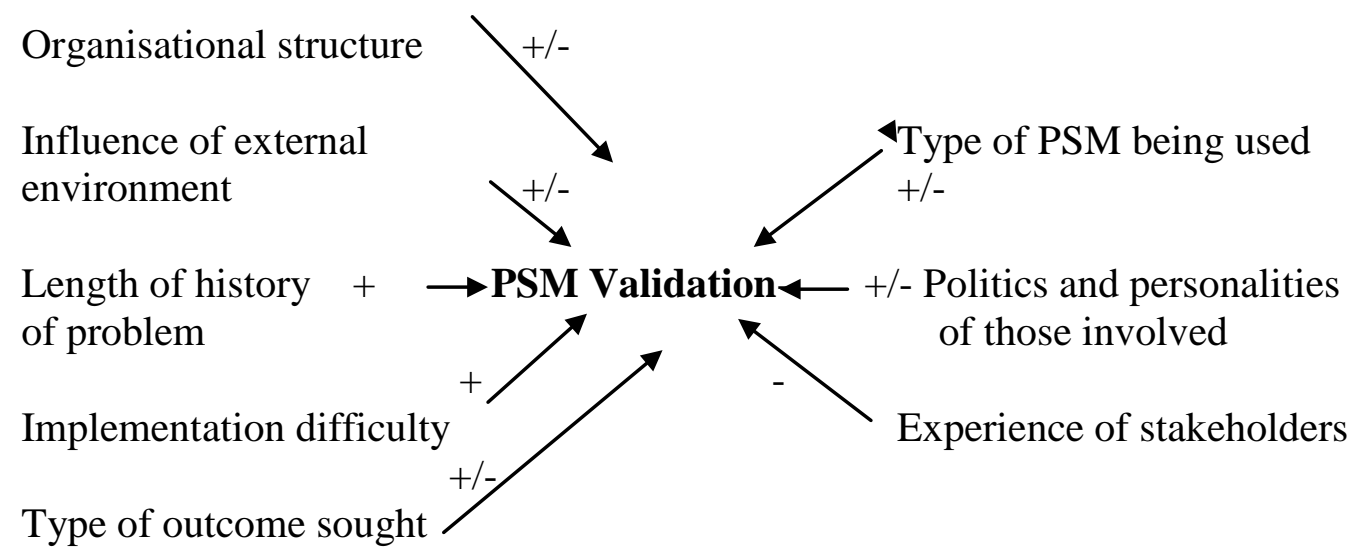

Figure 2

In order to establish if these factors argued to affect PSM validation have broad acceptance, a discussion document was circulated to a set of experts in PSM (see 
Appendix). The experts were asked both for their views about the factors in Section 3 , the factors listed above and other factors they might propose. Responses from the set of experts are tabulated in the version of the document shown in the Appendix.

The document used was circulated to authors of papers in the two special issues of Journal of the Operational Research Society (57:7 and 58:5) discussed in Section 4. The authors were contacted because they are acknowledged experts in PSM. These experts identified strongly the following five factors as influences on the conduct of PSM validation: level of risk/importance of decision, complexity of system/problem being modelled, significance of system to decision, system builder competence and contentiousness of decision. These were factors that also had been identified as important influences on DSS validation. Three other factors, probability of system reuse, decision deadline, and number of potential users of a system, were identified as having either a small influence (or views about the level of influence were mixed). Three other factors which were not relevant to DSS validation, but were identified strongly by the group of experts to be large influences on PSM validation were experience of stakeholders, type of outcome sought, including deliverables, and politics and personalities of those involved. A further five factors were felt to have some small influence (or views about the level of influence were mixed). These factors were organisational structure, influence of external environment, length of history of problem, implementation difficulty, and type of PSM being used. A number of other factors were also identified by respondents as being important. These include, amongst others, factors concerning facilitators, stakeholders and the environment in which PSM process will be conducted.

In the next section experiences of the authors with PSM will be described, and the way in which these experiences influence views on validation will be discussed.

\section{Our experiences: approaches to validation in collaborative settings}

Experiences of undertaking PSM in varying contexts including public service organizations, business organizations and community settings have led one of the 
authors to develop a collaborative approach to evaluating and validating both the process and the outcomes of PSM. The experience of applying PSM to the problem of designing information systems in business contexts quickly reveals some of the limitations of PSM. For example, involving all of the potential 'users' of a computerised IS in the design process may be prohibitive because of cost, or shift work, or due to a high overturn of personnel at a time of change for the company. PSM often involves many iterations of the learning cycle and proposals for intervention may implicate people who are unable to take part in the design process perhaps due to illness or maternity leave or who, for some other reason, are not included, perhaps they are new members of staff who joined after the project began. The time allowed for the design process may well be limited, excluding some from participation; or inclusion may be voluntary so meetings might be held immediately after a workday has ended, excluding those with childcare or family commitments (we can however ask if the participants were asked 'when would be a suitable time to meet?'). It does though become quickly apparent that it is essential to make some record of the learning process that can help newcomers, or people that have been absent for a while, to get quickly up to speed with the progress of the project. Here Checkland and Holwell's (1998) notion of recoverability is useful, and the wide variety of models created during PSM guided inquiry can go some way towards providing such a record (Champion and Stowell, 2003; Champion et al, 2005).

The type of models used in PSM will also impact on the degree of engagement achieved with the participants. For example, if spreadsheets are used to consider various alternatives this may result in a company's accountants and more technically minded staff being main advocates of the learning outcomes, and potentially excluding other staff with different skills and different concerns. It is important to ask if the type and combination of models used is appropriate and whether people are provided with sufficient training and support to fully participate in the PSM process.

One of the most difficult aspects of PSM is that the process of inquiry and the intervention into the problem situation will invariably result in some change to the relationships between people, those that participate and those impacted by the change. If PSM is being undertaken as an academic research project, it will also be important to consider the relationships between researchers and participants, and some reflection 
on the changing boundaries between the various groups will be necessary. There are very few models available to facilitate such reflection though Champion (2007) has developed the PEArL mnemonic ${ }^{1}$ (Champion and Stowell, 2001; 2003) and used this framework along with rich pictures and systems maps to try and help residents in a homeless shelter to reflect upon which relationships are supportive to them and which are unhelpful in their efforts to reintegrate into society.

Champion and Stowell (2003) argue that the manner in which a collaborative inquiry is undertaken is as important as the outcomes and this suggests that validating PSM requires reflection on both the PSM process (to establish legitimacy and authenticity) and outcomes. Developing approaches to PSM validation that can be undertaken not just by expert OR practitioners and academics, but by participants and interested individuals too, regardless of their educational background, should then be an important aim for the developers of PSM. Collaboration should be real and meaningful and include participation in the validation process and to do that we need to offer participants something practical that they can use for themselves.

\section{Towards a contingency theory}

Using the factors elicited from the consultations with experts, factors with large (more than 50\% support from experts consulted, as shown in Appendix) influence on validation are illustrated in Figure 3, where it is suggested that they fall into two clusters (a) 'people' factors and (b) ‘decision and outcome' factors. In Figure 3, the eight contingency factors are illustrated with +/- indicating whether they have a positive or negative impact on the likely amount of validation effort required. With three of the factors their impact could be either positive or negative. The factors are also split into the two groups discerned above. 'People' factors have mostly a negative link with validation effort, whereas 'decision and outcome' factors have mostly a positive link with validation effort.

\footnotetext{
${ }^{1}$ The PEArL mnemonic stands for Participants, Engagement, Authority, relationships and Learning. The $r$ is small to draw attention to it as the most important element of an inquiry process.
} 
Level of risk/importance of

decision.

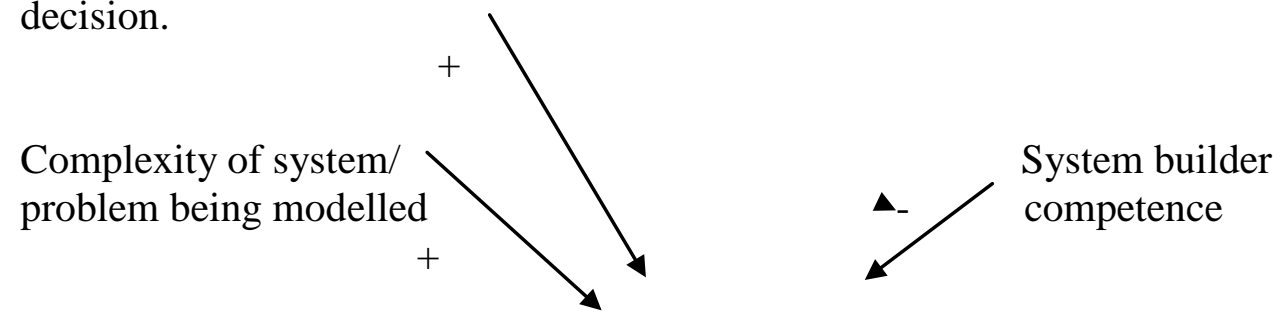

Significance of system $\rightarrow$
to decision

decision and outcome

people

Figure 3

A number of other conclusions can be drawn. First, a surprising number of contingency factors from traditional OR approaches to validation did carry over to PSM. These included the factors numbered 1-5 in Section 3. Second, organisational structure was felt by respondents not to be important. This surprised the authors and this result was not supported by evidence. In Champion et al (2005) a PSM guided project to design a new information system is described that took place in a large banking organization where the hierarchies and lines of reporting within which people operated and also the general flux of personnel (through promotion; redeployment, maternity leave etc) needed to be taken into account throughout the project. In contrast, the influence of politics and personalities was felt to be important, and so this factor may have overlapped too much with organisational structure. This underlines the argument in Champion and Stowell $(2001,2003)$ where they suggest that there is a need to distinguish between those undertaking the inquiry and those for whom any outcome was meant to bring improvement, as these two groups are not always exactly the same. Third, the type of PSM applied was not felt to be a significant factor. Again this surprised the authors because inquiry guided by a particular PSM (say SSM) can be quite different to undertaking Critical Systems Heuristics (Ulrich, 1983) for example. We had been expecting the reaction 'it all 
depends what kind of PSM you mean'. This 'oversight' by the respondents may in fact be an oversight by the authors. Fourth, 'history of the problem' and 'implementation difficulty' were perhaps less surprising candidates to be unsupported because they may have less bearing on the process of PSM and may be factors that respondents feel should not be allowed to cloud issues by allowing those participating in the PSM to get bogged down. Fifth, considering new factors that emerged from responses, 'social skills of facilitator' and 'stakeholders' views of the process' are not surprising inclusions because they contribute to establishing the authenticity of experience of those involved and the legitimacy of the process. Finally, the new factors 'perception that problem is worthy to address' and 'value of work carried out' although seemingly overlapping with 'importance of decision' seem to point to the fact that PSM may be used for problems that are important to address but might not, at least in the initial stages, be directly linked to a specific decision to be taken. Other factors mentioned by respondents, including requisite modelling, balance between perspective and objectivity, degree of granularity required, degree of ownership of issues, may point to further differences in validation when a decision/outcome is expected or a greater understanding of issues. These factors were not themselves validated, however they suggest that Figure 3 can be extended further.

It is not unreasonable that PSM, moreso than DSS, will be affected by 'people' factors. Working within a PSM framework will involve people extensively as participants in the structuring approach. That 'decision and outcome' factors should be considered to have a large influence on validation may be explained by the fact that decision and outcome are at the heart of OR. The factors in Figure 3 resonate also with the factors gleaned from the literature in OR and our own experiences of PSM in practice, so claims for validity for these factors can be advanced with a certain amount of justification.

The above discussion makes clear the relevance of many established contingency factors when considering the validation of the outcomes of a PSM guided inquiry. It is also clear that validation of outcomes is insufficient and that there is a need to establish the legitimacy of the PSM process itself. The processes applied to validating traditional OR models can be useful and lend robustness to the PSM process, although further work to legitimise the manner in which the inquiry process is undertaken will 
still be necessary. Practical experience from undertaking information systems design in business contexts would support this view, as traditional approaches to model validation do not establish the legitimacy of the process of inquiry and further work to address this issue always needs to be undertaken (Champion et al, 2005). This will involve undertaking activities to establish that participants worked at moving towards a greater understanding of the problem or the mess (to use Ackoff's term) in an ethical way and also considered issues such as longer term impacts on the wider environment and possible future consequences of any decisions made. Applying a contingency approach to validation of PSM, in addition to undertaking activities to establish legitimacy would also facilitate cross-disciplinary working and address some of the problems of miscommunication that can occur between professionals from different disciplines and educational backgrounds.

At this stage it is not valid to say that particular factors will influence the time required to validate a PSM by particular amounts. This could be the subject of further research. However, it is being proposed that these factors need to be taken into account when validating PSM and neglecting these issues may lead to consequences such as false conclusions being reached, stakeholders losing confidence in the PSM process, and time being wasted on flawed processes (and generating the need for redoing work). Applying this contingency approach addresses the issue raised by Romm (1996) where the outcomes of PSM (even if that outcome is only a greater appreciation of the problem) need to be checked using criteria from other approaches to prevent the problems of groupthink, or a lack of knowledge on the part of participants.

We suggest that the contingency factors we have set out here, which we do not pretend is a definitive list, have though been derived from the literature, expert opinion and practical experience, and so offer an important contribution to PSM validation. In practice, if PSM is undertaken as a collaborative endeavour, a variety of different approaches to validation may well be needed to facilitate a broad and public acknowledgement of validity amongst a wide and varied group of stakeholders and interested parties. We argue that these contingency factors offer such an approach; used alongside other frameworks such as PEArL (Champion, 2007) which offers 
insight into the manner in which PSM is undertaken, and the framework for comparing different PSM currently being developed by Midgley et al (2007), a broad consideration of the validity, credibility and reliability of PSM can be undertaken that will meet the needs of both experts and stakeholders alike. Such an approach would also facilitate multi-disciplinary work where professionals comfortable within one particular tradition (either 'soft' or 'hard') can find ways of working together and establish validity of their work in both an intellectually and ethically acceptable manner.

\section{References}

Ackoff R L (1981). The art and science of mess management. Interfaces 11(1): 2026.

Anastasakis L, Olphert C W and Wilson J M (2008). Experiences in using a contingency factor-based validation methodology for spreadsheet DSS. J Opl Res Soc 59:756-761.

Bødker S (1996). Creating Conditions for Participation: Conflicts and Resources in Systems Development. Hum Comp Inter 11: 215-236.

Champion D (2001). Navigating the Gap between Purposeful Action and a Serving Information System, Unpublished Ph.D. Thesis, Department of Computer and Information Sciences, De Montfort University, Milton Keynes.

Champion D (2007). Managing action research: the PEArL framework. Sys Prac Act Res 20: 455-465.

Champion, D (2008). Managing Collaborative research in dynamic organizational contexts. Int J Knowledge, Culture and Change Management 8: 149-158.

Champion D and Stowell F (2003). Validating action research field studies: PEArL. Sys Prac Act Res 16: 21-36.

Champion D, Stowell FA and O'Callaghan A (2005). Client-led information system creation (CLIC): navigating the gap. Inf Sys J, 15: 213-231.

Checkland P B (1985). From Optimizing to Learning: A Development of Systems Thinking for the 1990's. J Opl Res Soc, 36: 757-767.

Checkland P B (1995). Model Validation in Soft Systems Practice, Sys Res 12: 47-54. Checkland P B (1999). Systems Thinking, Systems Practice, with a 30 Years Retrospective on SSM. Chichester: John Wiley. 
Checkland P B and Holwell S E (1998). Action Research: Its Nature and Validity. Sys Prac Act Res. 11: 9-21.

Churchman C W(1970). Operations Research as a Profession. Management Science, 17: B37-53.

Ciborra C (2002). The Labyrinth of Information: Challenging the Wisdom of Systems. Wiley: Chichester.

Connell N A D (2001). Evaluating soft OR: some reflections on an apparently unsuccessful implementation using a Soft Systems Methodology (SSM) based approach. J Opl Res Soc 52: 150-160.

Dash D P (1999). Current debates in action research, Sys Prac Act Res 12: 457-492. Dery K, Landry M and Banville C (1993). Revisiting the issue of model validation in OR: an epistemological view. Eur J Opl Res 66: 166-183.

Finlay P N (1998). On evaluating the performance of GDSSs. Eur J Opl Res 107: 193-201.

Finlay P N and Wilson J M (1987). The paucity of model validation in operational research projects. J Opl Res Soc 38: 303-308.

Finlay P N and Wilson J M (1997). Validity of decision support systems: towards a validation methodology. Sys Res Behavl Sc 14: 169-182.

Finlay P N and Wilson J M (2000). A survey of contingency factors affecting the validation of end-user spreadsheet based decision support systems. J Opl Res Soc 51: 949-958.

Fishman G S and Kiviat P J (1968) The statistics of discrete event simulation. Simulation, April.

Franco L A (2006). Forms of conversation and problem structuring methods: a conceptual development. J Opl Res Soc 57: 813-821.

Gass S I (1983) Decision aiding models: validation, assessment, and related issues for policy analysis. Opns Res 31: 603-631.

Gregory A J and Jackson M C (1992a). Evaluating organizations: A systems and contingency approach. Systems Practice 5: 37-60.

Gregory A J and Jackson M C (1992b). Evaluation methodologies: A system for use. Journal of the Operational Research Society, 43, 19-28.

den Hengst M, de Vreede G-J and Maghnouji R (2007). Using soft OR principles for collaborative simulation: a case study in the Dutch airline industry. J Opl Res Soc 58: 669-682. 
Holwell SE (1997). Soft Systems Methodology and its Role in Information Systems. Unpublished Ph.D. Thesis, Department of Management Science, University of Lancaster.

Jackson M C (1982). The nature of soft systems thinking: The work of Churchman, Ackoff and Checkland. Journal of Applied Systems Analysis, 9, 17-29.

Jackson M C (2000). Systems Approaches to Management. Plenum: New York Keys P (2006). On becoming expert in the use of problem structuring methods. $\quad J$ Opl Res Soc 57: 822-829.

Kotiadis K and Mingers J (2006). Combining PSM with hard OR methods: the philosophical and practical challenges. J Opl Res Soc 57: 856-867.

Landry M, Malouin J-L and Oral M (1983). Model validation in operations research. Eur J Opl Res 14: 207-220.

Märtensson P and Lee A S (2004). Dialogical Action Research at Omega Corporation. MIS Quarterly 28: 507-536.

Midgley G (1989). Critical Systems: The Theory and Practice of Partitioning Methodologies. In, Proceedings of the 33rd Annual Meeting of the International Society for the Systems Sciences, held in Edinburgh, Scotland, on 2-7 July 1989. Midgley G (1990). Creative Methodology Design. Systemist, 12, 108-113. Midgley G (1992). Pluralism and the Legitimation of Systems Science. Systems Practice, 5, 147-172.

Midgley G (2000). Systemic Intervention: Philosophy, Methodology, and Practice. Kluwer/Plenum: New York.

Midgley G, Ahuriri-Driscoll A, Baker V, Foote J, Hepi M, Taimona H, RogersKoroheke M, Gregor J, Gregory W, Lange M, Veth J, Winstanley A and Wood A (2007). Practitioner identity in systemic intervention: Reflections on the promotion of environmental health through Maori community development. Sys Res Behav Sc 24: 233-247.

Mingers J C (1980). Towards an appropriate social theory for applied systems thinking: Critical theory and soft systems methodology. Journal of Applied Systems Analysis, 7, 41-50.

Mingers J C (1984). Subjectivism and soft systems methodology—A critique. Journal of Applied Systems Analysis, 11, 85-103. 
Mingers J (2003). A classification of the philosophical assumptions of management science methods. J Opl Res Soc 54: 559-570.

Miser H J (1993). A foundational concept of science appropriate for validation in operational research. Eur J Opl Res 66: 204-215.

Montibeller G. and Belton V. (2006). Causal maps and the evaluation of decision options - a review. J Opl Res Soc 57: 779-791.

Morton A, Ackermann F and Belton V (2007). Problem structuring without workshops? Experiences with distributed interaction within a PSM process. J Opl Res Soc 58: 547-556.

O’Brien F and Meadows M (2007). Developing a visioning methodology: Visioning Choices for the future of operational research. J Opl Res Soc 58: 557-575.

Olphert C W and Wilson J M (2004). Validation of decision-aiding spreadsheets: the influence of contingency factors. J Opl Res Soc 55: 12-22.

Ormerod R (2008). The transformation competence perspective, J Opl Res Soc 59: 1435-1448.

Oral M and Kettani O (1993). The facets of modelling and validation process in operations research. Eur J Opl Res 66: 216-234.

Pala O, Vennix J A M and van Mullekom T (2003). Validity in SSM: negelected areas. J Opl Res Soc 54: 706-712.

Papamichail K N, Alves G, French S, Yang J B and Snowdon R (2007). Facilitation practices in decision workshops. J Opl Res Soc 58: 614-632.

Pawson R and Tilley N (1997). Realistic Evaluation. Sage: London.

Ritchey T (2006). Problem structuring using computer-aided morphological analysis. J Opl Res Soc, 57: 792-801.

Robinson S (2008). Conceptual modelling for simulation. Part 1: definitions and requirements. J Opl Res Soc, 59: 278-290.

Romm N R A (1996). Inquiry-and-intervention in systems planning: Probing methodological rationalities. World Futures, 47, 25-36.

Rosenhead J (2006). Past, present and future of problem structuring methods. J Opl Res Soc, 57: 759-765.

Rosenhead J (1996). What's the problem? An introduction to problem structuring methods. Interfaces 26(6): 117-131. 
Shaw D (2006). Journey Making group workshops as a research tool. J Opl Res Soc, 57: 830-841.

Smail D (2001). The Nature of Unhappiness. London: Random House.

Taket A R and White L A (2000). Partnership and Participation: Decision-making in the Multiagency Setting. Chichester: Wiley.

Ulrich W (1983). Critical heuristics of Social Planning: A New Approach to Practical Philosophy. Haupt: Berne.

USGAO (1979) Guidelines for model evaluation. PAD-79-17. USGAO:

Washington.

Vickers G (1965). The Art of Judgement. A Study of Policy Making. Chapman and Hall: London.

Vo H V, Chae B and Olson D (2007). Developing unbounded systems thinking: using causal mapping with multiple stakeholders within a Vietnamese company. J Opl Res Soc 58: 655-668.

White L (2006). Evaluating problem-structuring methods: developing an approach to show the value and effectiveness of PSM. J Opl Res Soc 57: 842-855.

Winter M (2006). Problem structuring in project management: and application of soft systems methodology (SSM). J Opl Res Soc 57: 802-812.

\section{Appendix}

1. Contingency factors known to influence DSS validation. Do they also influence PSM validation? (please indicate in the table) (Responses are tabulated as percentages in italic font.)

\begin{tabular}{|c|c|c|c|}
\hline & \multicolumn{3}{|c|}{ Influence on PSM validation } \\
\hline Factor & None & Small & Large \\
\hline Level of risk/importance of decision & & $10 \%$ & $90 \%$ \\
\hline $\begin{array}{c}\text { Complexity of system/problem being } \\
\text { modelled }\end{array}$ & & $10 \%$ & $90 \%$ \\
\hline $\begin{array}{c}\text { Significance of system to decision } \\
\text { System builder competence }\end{array}$ & & $40 \%$ & $60 \%$ \\
\hline Contentiousness of decision & & $20 \%$ & $100 \%$ \\
\hline Probability of system re-use & $50 \%$ & $50 \%$ & \\
\hline Decision deadline & $25 \%$ & $25 \%$ & $50 \%$ \\
\hline Number of potential users of system & $20 \%$ & $40 \%$ & $40 \%$ \\
\hline
\end{tabular}


2. Contingency factors which were not relevant for DSS validation but might influence PSM validation. Do you agree? (please indicate in the table)

\begin{tabular}{|c|c|c|c|}
\hline & \multicolumn{3}{|c|}{ Influence on PSM validation } \\
\hline Factor & None & Small & Large \\
\hline Experience of stakeholders & $10 \%$ & $25 \%$ & $65 \%$ \\
\hline Organisational structure & $10 \%$ & $50 \%$ & $40 \%$ \\
\hline $\begin{array}{c}\text { Influence of external environment } \\
\text { Type of outcome sought, including } \\
\text { deliverables }\end{array}$ & $10 \%$ & $50 \%$ & $20 \%$ \\
\hline $\begin{array}{c}\text { Politics and personalities of those } \\
\text { involved }\end{array}$ & & & $90 \%$ \\
\hline $\begin{array}{c}\text { Length of history of problem } \\
\text { Implementation difficulty }\end{array}$ & $10 \%$ & $40 \%$ & $50 \%$ \\
\hline Type of PSM being used & $20 \%$ & $40 \%$ & $50 \%$ \\
\hline
\end{tabular}

3. Are there other contingency factors which you think would influence PSM validation? (please indicate in the table)

\begin{tabular}{|l|l|l|}
\hline & \multicolumn{2}{|c|}{$\begin{array}{c}\text { Influence on PSM } \\
\text { validation }\end{array}$} \\
\hline Description of Factor & Small & Large \\
\hline & & \\
\hline & & \\
\hline & & \\
\hline & & \\
\hline
\end{tabular}

Responses: Large influences

Social skills of facilitator

Requisite modelling

Balance between perspective and objectivity

Stakeholders' views of process

Perception that problem is worthy to address

Degree of granularity required

Degree of ownership of issues

Perceived value of the work carried out

Responses: Small influences

Invitation for further work

Environment in which PSM employed (room/people)

Setup done by facilitator

Who is doing validation and from whose perspective it is valid.

Responses: Non-specific level of influence

Are you validating outcome effect etc 